\title{
Plant Biotechnology for Food Security: New Frontiers
}

\author{
T. R. Sharma • M. L. Lodha • P. Ananda Kumar • \\ R. Srinivasan $\cdot$ S. R. Bhat $\cdot$ C. Viswanathan
}

Published online: 12 September 2012

(C) Society for Plant Biochemistry and Biotechnology 2012

Global food and nutritional security is a major area of concern. Traditional technologies have largely run their course, and we are witnessing plateauing of yields of major crops. The climate change scenario and diminishing natural resources for crop production pose additional challenges to food production in a sustainable manner. Among the available options, biotechnology offers opportunities for accelerated crop improvement for attaining food and nutritional security. The Bt-cotton in India, and glyphosate herbicide tolerant soybean in the US and South America, best illustrate the potential of transgenic technology. The Golden rice nutritionally fortified for provitamin A is in the pipeline. Similarly, the sequencing of important crop genomes and rapidly accumulating genomic resources across crops have opened novel opportunities for precision breeding of crops. The recent commercial release of improved rice varieties in India testifies the power of molecular Marker-Assisted Selection (MAS) approach for accelerated and precision breeding of varieties. The technique is now being extended to other crops. Successful utilization of the

T. R. Sharma $(\varangle) \cdot$ P. A. Kumar · R. Srinivasan · S. R. Bhat National Research Centre on Plant Biotechnology,

Pusa Campus,

New Delhi 110 012, India

e-mail: trsharma@nrcpb.org

M. L. Lodha

Flat \#2064, Joy Apartments, Plot No- 2, Sector-2,

Dwarka Phase -1,

New Delhi 110 075, India

C. Viswanathan

Division of Plant Physiology,

Indian Agricultural Research Institute,

Pusa Campus,

New Delhi 110 012, India vast amount of genomic data and resources that are being generated in recent years would require up gradation of infrastructure and skills, and regular interaction and collaboration with the international community. Further, the transgenic technology has also highlighted the urgent need for effective science communication with the general public to allay fears of new technologies. In view of these, the Society for Plant Biochemistry and Biotechnology and the National Research Centre on Plant Biotechnology, in association with the Indian Agricultural Research Institute, New Delhi organized the First International Conference on "Plant Biotechnology for Food Security: New Frontiers" from February 21-24, 2012, New Delhi, India. More than 600 Scientists and students from all over the globe attended the conference. Eminent scientists participated in the deliberations in seven different sessions spread over three days: (a) Biochemistry and Metabolic Engineering, (b) Developmental Biology, (c) Biotic and Abiotic Stress Management (d) Genomics and Bioinformatics, (e) Molecular Plant Breeding, (f) Nanobiotechnology and Diagnostics, and (g) Biotechnology Education, Biosafety and Public Awareness.

The presentations were a veritable treat. Due to obvious constraints of space and logistics, we cannot provide you here full coverage of all the presentations. Instead, in this Special issue of the Journal of Plant Biochemistry and Biotechnology, we have attempted to compile a comprehensive set of 17 selected invited presentations from leading authorities from various fields.

We hope that the scientific community in general and the plant biologists in particular will find this issue of JPBB very timely and useful. The editorial committee sincerely thanks all the contributing authors for their support.

\section{Editors}

